\section{Commentary: Why not MAG-nify the benefit in patients with diabetes?}

\author{
Jennifer S. Lawton, MD
}

In their recent review, Akhrass and Bakaeen ${ }^{1}$ nicely detail why patients with diabetes and multivessel coronary artery disease benefit from coronary artery bypass grafting $(\mathrm{CABG})$ as the coronary revascularization method of choice. Benefits include prolonged survival and reduced cardiovascular events. These have been suggested since the first Bypass Angioplasty Revascularization Investigation trial in $1996^{2}$ and strongly reinforced by the more contemporary Future Revascularization Evaluation in Patients with Diabetes Mellitus: Optimal Management of Multivessel Disease trial ${ }^{3,4}$ reported in 2012 and 2019. Akhrass and Bakaeen ${ }^{1}$ also summarize the data supporting the use of multiple arterial grafting (MAG) and the resultant added benefits associated with their use in patients with diabetes.

Diabetes is a significant risk factor for cardiovascular disease that is especially magnified in women. ${ }^{5,6}$ Patients with diabetes are known to have more diffuse coronary artery disease that is often associated with smaller vessels and significant calcification. Patients with diabetes are known to represent a high-risk group when undergoing CABG. Multiple large, retrospective studies with long-term follow-up have documented benefit with use of MAG in the setting of diabetes. ${ }^{7-10}$ Patients with diabetes have largely been evaluated as subgroup analyses of randomized controlled trials and meta-analyses comparing revascularization strategies (eg, percutaneous intervention vs CABG) ${ }^{11,12}$; however, use of MAG remains low in Europe (3.8\%-34.2\%) and North America (9.9\%-27.8\%). ${ }^{13}$ Thus, comparisons

\footnotetext{
From the Division of Cardiac Surgery, Department of Surgery, Johns Hopkins University, Baltimore, Md.

Disclosures: The author reported no conflicts of interest.

The Journal policy requires editors and reviewers to disclose conflicts of interest and to decline handling or reviewing manuscripts for which they may have a conflict of interest. The editors and reviewers of this article have no conflicts of interest.

Received for publication Feb 19, 2021; revisions received Feb 19, 2021; accepted for publication Feb 22, 2021; available ahead of print Feb 26, 2021

Address for reprints: Jennifer S. Lawton, MD, Division of Cardiac Surgery, Department of Surgery, Johns Hopkins Hospital, 1800 Orleans St, Zayed 7107, Baltimore, MD 21287 (E-mail: jlawton4@jhmi.edu).

J Thorac Cardiovasc Surg 2022;164:123-4

$0022-5223 / \$ 36.00$

Copyright (c) 2021 by The American Association for Thoracic Surgery

https://doi.org/10.1016/j.jtcvs.2021.02.077
}

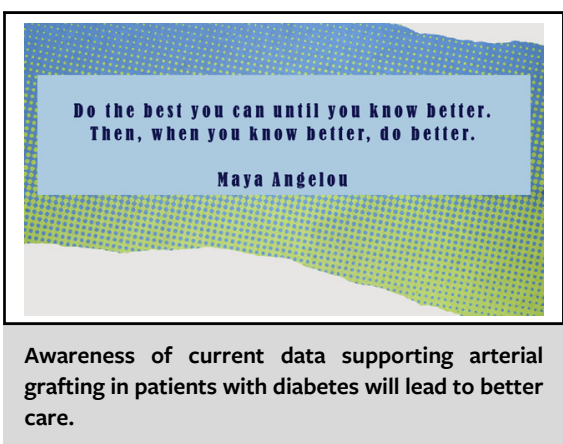

CENTRAL MESSAGE

Patients with diabetes and multivessel coronary artery disease have better outcomes with CABG for revascularization. This benefit can be further MAGnified with the addition of multiarterial grafting.

between MAG and single arterial grafting in patients with diabetes are difficult.

The obvious question is do we need a large randomized trial of MAG versus single arterial grafting in patients with diabetes to determine whether or not incremental benefit is obtained? Perhaps the Randomized Comparison of the Outcome of Single versus Multiple Arterial Grafts trial will add to this body of data. ${ }^{14}$ It seems intuitive that MAG should provide the same benefits (or greater) to patients with and without diabetes based on the physiologic differences between arterial and venous grafts and the diffuse disease found in patients with diabetes. Internal thoracic artery grafts are known to have superior patency due to resistance to atherosclerosis. Arterial grafts are associated with endothelial nitric oxide production and less progression of native atherosclerotic disease within the proximal left anterior descending artery after grafting, they remain elastic at arterial pressures, and they are more sensitive than veins to vasodilators. ${ }^{15,16}$

There are barriers to the use of arterial grafts in patients with diabetes, including perceived increased risk of sternal wound infection (although this may be largely mitigated by skeletonization of grafts), increased time and technical complexity, concerns for spasm, concerns for hand complications, lack of desire to teach trainees, lack of qualified assistant to harvest, concerns regarding adequate flow or size, subclavian stenosis, chest wall radiation, and patient preference. However, strong evidence now supports that the use of 


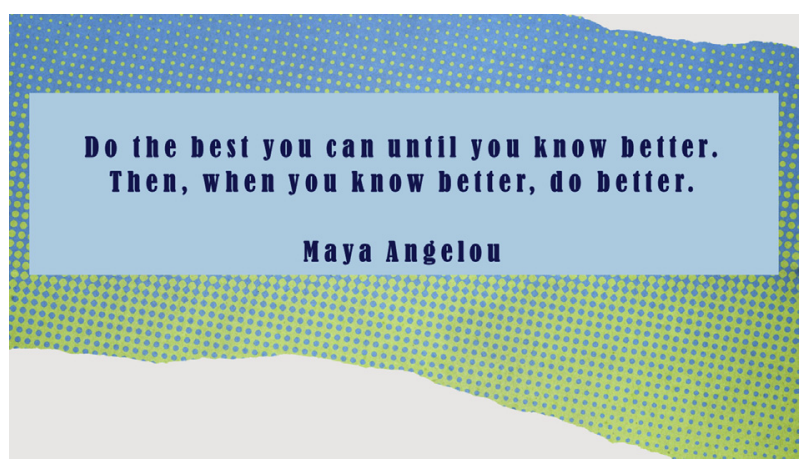

FIGURE 1. Awareness of current data supporting arterial grafting in patients with diabetes will lead to better care.

arterial grafting is associated with improved patency, prolonged survival, and reduced cardiovascular events compared with venous grafting. Thanks to the excellent review by Akhrass and Bakaeen, ${ }^{1}$ we now know better and can do better for our patients (Figure 1). Increased surgeon awareness of the current data supporting arterial grafting in patients with diabetes will lead to prolonged survival and better care.

\section{References}

1. Akhrass R, Bakaeen F. The advantage of surgical revascularization in diabetic patients with multivessel disease: more arterial conduits, more benefit. J Thorac Cardiovasc Surg. 2022;164:119-22.

2. Bypass Angioplasty Revascularization Investigation (BARI) Investigators. Comparison of coronary bypass surgery with angioplasty in patients with multivessel disease. N Engl J Med. 1996;335:217-25.

3. Farkouh ME, Domanski M, Sleeper LA, Siami FS, Dangas G, Mack M, et al. Strategies for multivessel revascularization in patients with diabetes. $N$ Engl J Med. 2012;367:2375-84.
4. Farkouh ME, Domanski M, Dangas GD, Godoy LC, Mack MJ, Siami FS, et al. Long-term survival following multivessel revascularization in patients with diabetes: the FREEDOM follow-on study. J Am Coll Cardiol. 2019;73: 629-38.

5. Garcia M, Mulvagh SL, Merz CN, Buring JE, Manson JE. Cardiovascular disease in women: clinical perspectives. Circ Res. 2016;118:1273-93.

6. Sharma K, Gulati M. Coronary artery disease in women: a 2013 update. Glob Heart. 2013;8:105-12.

7. Buxton BF, Shi WY, Tatoulis J, Fuller JA, Rosalion A, Hayward PA. Total arterial revascularization with internal thoracic and radial artery grafts in triple-vessel coronary artery disease is associated with improved survival. $J$ Thorac Cardiovasc Surg. 2014;148:1238-43.

8. Raza S, Sabik JF III, Masabni K, Ainkaran P, Lytle BW, Blackstone EH. Surgical revascularization techniques that minimize surgical risk and maximize late survival after coronary artery bypass grafting in patients with diabetes mellitus. $J$ Thorac Cardiovasc Surg. 2014;148:1257-64.

9. Deb S, Singh SK, Moussa F, Tsubota H, Une D, Kiss A, et al. The long-term impact of diabetes on graft patency after coronary artery bypass grafting surgery: a substudy of the multicenter Radial Artery Patency Study. J Thorac Cardiovasc Surg. 2014;148:1246-53.

10. Yamaguchi A, Kimura N, Itoh S, Adachi K, Yuri K, Okamura H, et al. Efficacy of multiple arterial coronary bypass grafting in patients with diabetes mellitus. Eur J Cardiothorac Surg. 2016;50:520-7.

11. Verma S, Farkouh ME, Yanagawa B, Fitchett DH, Ahsan MR, Ruel M, et al. Comparison of coronary artery bypass surgery and percutaneous coronary intervention in patients with diabetes: a meta-analysis of randomised controlled trials. Lancet Diabetes Endocrinol. 2013;1:317-28.

12. Tam DY, Dharma C, Rocha R, Farkouh ME, Abdel-Qadir H, Sun LY, et al. Longterm survival after surgical or percutaneous revascularization in patients with diabetes and multivessel coronary disease. J Am Coll Cardiol. 2020;76:1153-64.

13. Gaudino M, Alexander JH, Bakaeen FG, Ballman K, Barili F, Calafiore AM, et al. Randomized comparison of the clinical outcome of single versus multiple arterial grafts: the ROMA trial-rationale and study protocol. Eur J Cardiothorac Surg. 2017;52:1031-40.

14. Gaudino M, Chikwe J, Falk V, Lawton JS, Puskas JD, Taggart DP. Transatlantic editorial: the use of multiple arterial grafts for coronary revascularization in Europe and North America. J Thorac Cardiovasc Surg. 2020;159:2254-9.

15. Cox JL, Chiasson DA, Gotlieb AI. Stranger in a strange land: the pathogenesis of saphenous vein graft stenosis with emphasis on structural and functional differences between veins and arteries. Prog Cardiovasc Dis. 1991;34:45-68.

16. Motwani JG, Topol EJ. Aortocoronary saphenous vein graft disease: pathogenesis, predisposition, and prevention. Circulation. 1998;97:916-31. 